\title{
PEMBINAAN DAN PEMBERIAN BANTUAN KEPADA SEKOLAH PAUD (PENDIDIKAN ANAK USIA DINI) "PEDULI ANAK BANGSA" DI DESA PONDOK KUBANG, KECAMATAN PONDOK KUBANG, KABUPATEN BENGKULU TENGAH
}

\section{DEVELOPMENT AND AID PROVISION FOR EARLY CHILDHOOD EDUCATION SCHOOL (PAUD) "PEDULI ANAK BANGSA" AT PONDOK KUBANG VILLAGE, PONDOK KUBANG SUB-DISTRICTM, CENTRAL BENGKULU}

\author{
Oleh: \\ Sri Hartati, $d k k$. \\ Jurusan Sosiologi, FISIP UNIB
}

\begin{abstract}
This community service activity was focused on the early childhood education school (PAUD or Pendidikan Anak Usia Dini), because this institution is now becoming a national public movement. Early childhood who are in the age range of 0 to 6 years old. At that time the chidren are experiencing a process of growth and development in various aspects, such as: physical, social, language and cognitive skills very quikly and is fundametal for their future. In fact, neurosccience experts call this developmental period of childhood as the golden age that between the age of 0 to 6 years old can give full attention by providing a good education for their children. Because of the importance of early childhood education, then this community service activity intended to provide guidance and aids to an early childhood education school (PAUD) whose condition is very poor, namely that in Pondok Kubang village.This PAUD was founded in 2008 on the initiative of the World Bank. However, since three years ago the World Bank has no longer given funds. Asd a result, this PAUD has become very poor. Almost all of the existing toys and books are now damaged. Event funds to provide incentives for teachers were not available. The metod used in this community service activity is an enhancement to the teachers by discussing and providing aids in the form of short-leg table to write, books of folklore, world story books, studying media, puzzles, and other game tools. All aids are very useful, both for teachers and students.
\end{abstract}

Keywords: early childhood education, study aid material, national movement, development

\section{PENDAHULUAN}

Undang-Undang (UU) Nomor 20 Tahun 2003 tentang Sisitem pendidikan Nasional telah mengamanatkan dilaksanakan pendidikan kepada seluruh rakyat Indonesia sejak usia dini, yakni sejak anak dilahirkan. Disebutkan secara tegas dalam undang-undang tersebut bahwa Pendidikan Anak Usia Dini (PAUD) adalah suatu upaya pembinaan yang ditujukan kepada anak sejak lahir sampai dengan usia enam tahun yang dilakukan melalui pemberian 
rangsangan pendidikan untuk membantu pertumbuhan dan perkembangan jasmani dan rohani agar anak memiliki kesiapan dalam memasuki pendidikan lebih lanjut (Pasal 1, butir 14).

Selanjutnya, dinyatakan secara tegas dalam UU Nomor 20 Tahun 2003 (pasal 28) antara lain bahwa PAUD diselenggarakan sebelum jenjang pendidikan dasar, dan PAUD dapat diselenggarakan dalam jalur pendidikan formal (seperti Taman Kanak-Kanak, Raudhatul Athfal atau bentuk lain yang sederajat), jalur pendidikan formal (seperti Taman Penitipan Anak, Kelompok Bermain, atau bentuk lain yang sederajat), serta jalur pendidikan informal (seperti PAUD dalam keluarga atau yang diselenggarakan oleh lingkungan).

Pemerintah sangat memperhatikan pendidikan bagi anak usia dini, sehingga PAUD sekarang ini sudah menjadi gerakan masyarakat. Pemerintah berharap agar anak-anak yang berusia dini dapat tertampung di lembaga PAUD ini. Maka diharapkan setiap desa di seluruh Indonesia ada satu PAUD. Namun sayangnya berdasarkan hasil sensus Tahun 2005 masih ada sekitar 26 juta anak usia dini di Indonesia yang belum terlayani kebutuhannya pada bidang pendidikan. Pada sisi kelembagaan pendidikan anak usia dini yang ada baru sebesar $72 \%$ angka partisipasi kasar (APK). Hal ini diperburuk dengan masih rendahnya kualitas penyelenggarakan lembaga pendidikan anak usia dini dilihat dari aspek standart program yang diberikan, proses pembelajaran yang belum mengakomodasi kebutuhan anak, kualitas dan kualifikasi tenaga pendidik anak usia dini yang masih tergolong rendah (Suprapti, 2007: 2).

Pentingnya PAUD sudah tidak diragukan lagi, namun demikian masih banyak orangtua yang mengganggap Pendidikan Anak Usia Dini (PAUD) sebagai pendidikan sekunder, sehingga banyak orangtua yang lebih memilih untuk langsung menyekolahkan anaknya ke Sekolah Dasar. Sampai sekarang masih banyak orangtua, terutama yang ada di desa-desa yang belum mengerti akan pentingnya Pendidikan Anak Usia Dini (PAUD) ini.

Pemerintah telah memberikan perhatian terhadap pendidikan bagi anak-anak sedini mungkin dengan Program PAUD di Indonesia dimulai dalam skala besar oleh pemerintah sejak terbentuknya Direktorat PAUD (saat itu PADU) pada tahun 2002. Menurut Lydia Freyani Hawadi selaku Direktur Jenderal Pendidikan Anak Usia Dini Nonformal dan Informal (PAUD), sebaiknya anak-anak usia 2-6 tahun diikutkan PAUD karena di tempat ini anak-anak mendapat pengalaman, sosialisasi, serta pengajaran pada masa terpenting dalam pertumbuhan dan perkembangan mereka.

\section{METODE PENGABDIAN}

Langkah-langkah untuk merealisasi tujuan PPM ini meliputi: (a) melakukan musyawarah antara tenaga pendidik (guru) PAUD dengan Tim PPM Dosen Sosiologi untuk membicarakan bentuk pembinaan dan bantuan seperti apa yang dibutuhkan oleh PAUD, (b) Melakukan semacam diskusi atau dialog dengan para tenaga pendidik (guru) tentang bagaimana metode pembelajaran yang tepat untuk anak-anak PAUD, karena 
pembelajaran di PAUD, berbeda dengan pembelajaran di jenjang pendidikan yang lain, (c) Pemberian bantuan berupa bangku-bangku untuk alas menulis, buku-buku cerita, alat-alat peraga dan gambar-gambar yang digunakan dalam proses pembelajaran di PAUD, (4) penyerahan semua bantuan dengan disaksikan oleh bapak kepala desa Pondok Kubang dan Ketua PAUD, para orangtua murid, para pendidik (guru) dan anak-anak PAUD.

Keterkaitan kegiatan pengabdian pada masyarakat ini adalah terjalinnya kemitraan dengan pengelola PAUD "Peduli Anak Bangsa" karena kegiatan ini dalam upaya untuk membenahi atau memperbaiki lembaga PAUD yang ada di desa ini. Dahulu PAUD ini berdiri atasi sponsori dari Bank Dunia, maka, fasilitas-fasilitas untuk pendirian sebuah PAUD sudah lengkap seperti: fasilitas bermain di halaman seperti permainan ayunan, plosotan, dan lain-lain sudah ada. Bahkan perlengkapan untuk proses belajar mengajarnyapun sudah ada seperti, buku-buku cerita, buku-buku bergambar, alat-alat peraga, alat-alat permainan yang yang diperuntukkan di dalam ruangan seperti puzzle juga sudah lengkap. Hanya saja, tempat untuk belajarnya masih menumpang di rumah salah satu penduduk. Para tenaga pendidiknyapun setiap bulannya mendapat uang insentif sebesar Rp 250.000/bulan. Namun sayang bantuan dari Bank Dunia ini hanya berjalan selama tiga tahun saja. Sekarang ini, setelah tiga tahun berlalu kondisi PAUD tersebut sangat memprihatinkan oleh karena itu, Tim PPM berusaha untuk membina dan memberi bantuan agar PAUD ini dapat berkembang dan meningkat lebih baik.

\section{HASIL DAN PEMBAHASAN}

Setelah pengajuan proposal diterima oleh LPPM UNIB maka kami Tim PPM, kemudian rutin melakukan komunikasi terutama kepada para pendidiknya (guru) karena mereka lah yang setiap harinya mengelola berjalannya PAUD ini dan yang selalu berhadapan dengan anak-anak muridnya. Para pendidiklah yang merasakan akan kebutuhan-kebutuhan yang dirasa masih kurang, dan amat dibutuhkan untuk kelancaran dalam proses belajar mengajarnya.

Sekarang ini PAUD "Peduli Anak Bangsa" menempati salah satu ruangan dari rumah yang berbentuk rumah panggung, milik salah satu warga. Tepatnya di ruang bawah paling depan dengan ukuran sekitar 3 x 8 meter, dengan dinding papan dan anyaman bambu yang kondisinya sudah bolong-bolong. Ruangan seluas itu pun tidak digunakan semuanya, karena ruangan itu masih diambil sekitar 3 × 2 m, yang diberi sekat pendek untuk meletakkan barang-barang yang sudah tidak terpakai lagi atau sudah rusak. Jadi kalau kita masuk ruangan yang untuk belajar terlihat barang yang rusak menumpuk tidak karuan, sehingga mengganggu pemandangan.

Di dalam ruangan yang untuk belajar, tidak ada meja dan kursi seperti sekolahsekolah atau PAUD-PAUD pada umumnya. Ruangan belajarnya hanya dilapisi karpet yang dari plastik dan juga sudah banyak yang rusak. Jadi anak-anak PAUD kalau belajar duduk di lantai, bahkan, kalau menulis atau menggambar, juga di lantai akibatnya anak- 
anak harus membungkuk sehingga anak-anak tidak tahan lama, karena punggungnya sakit. Dinding ruangannya dihiasi atau ditempeli dengan gambar-gambar yang sudah lama dan sudah lusuh. Dan di sudut ruangan ada sebuah rak kecil dari kayu yang untuk meletakkan buku-buku yang masih ada dan sebuah keranjang yang untuk menyimpan alat-alat permainan yang sudah rusak, tidak utuh lagi tapi masih digunakan.

Kondisi PAUD di luar ruangan, tepatnya di halaman sebelah kanan, masih ada sisa alat permainan anak dua (2) buah yang kondisinya sudah rusak, seperti ayunan tapi sudah tidak bisa digunakan lagi, jadi hanya sekedar dinaik-naiki saja oleh anak-anak. Di depan rumah, di bagian atas terpasang papan nama PAUD "Peduli Anak Bangsa" tapi papan itu sebenarnya harus diganti karena di papan nama itu masih tertulis bahwa desa Pondok Kubang itu, kecamatannya masih Pondok Kelapa. Padahal sekarang ini desa Pondok Kubang, kecamatannya Pondok Kubang, Kabupaten Bengkulu Tengah. Hal ini terjadi karena, sampai sekarang tidak ada dana untuk mengganti papan nama tersebut.

Dahulu sewaktu masih di danai oleh Bank Dunia, anak-anak PAUD tidak dipungut bayaran, dan para tenaga pendidiknya (guru), setiap bulannya mendapat insentif Rp 250.000/bulan. Tapi sekarang ini untuk mengelola PAUD tersebut, agar tetap bisa berjalan maka setiap anak dipungut bayaran Rp 15.000/bulannya. Uang itu dipergunakan untuk operasional PAUD dan sedikit memberi insentif bagi para pendidiknya yang setiap bulannya hanya Rp.100.000,-. Namun demikian, dari desa Pondok Kubang melalui anggaran desanya, setiap bulan tenaga pendidiknya (guru) mendapat bantuan Rp 20.000,-. Melihat jumlah uang yang diterima setiap bulannya, maka boleh dikatakan kalau para pendidiknya, hanya pengabdian atau sukarela saja, karena tidak mencari materi.

Dengan keberadaan PAUD tersebut, membuat warga desa Pondok Kubang dan desadesa di sekitarnya tidak kesulitan lagi untuk menitipkan anaknya untuk belajar. Oleh karena itu, mereka merasa tidak keberatan walaupun dipungut bayaran Rp 15.000 setiap bulannya. Yang terpenting bagi warga, anak-anaknya dapat sekolah sehingga mendapat pendidikan yang baik, dibandingkan kalau anak-anak mereka hanya tinggal di rumah atau berkeliaran tidak karuan. Disini para orangtua sudah sadar bahwa anak-anak usia dini harus mendapatkan pendidikan yang baik.

Sekarang ini PAUD "Peduli Anak Bangsa" dikelola oleh tiga orang sebagai tenaga pendidik (guru). Ketiganya ini tidak ada yang mempunyai ijazah PAUD ataupun sertifikasi untuk mengajar. Kalaupun ada kursus-kursus atau pelatihan-pelatihan yang diselenggarakan oleh kabupaten atau diknas provinsi Bengkulu, mereka tidak pernah diikutsertakan, sehingga mereka kurang mempunyai bekal untuk mengajar anak-anak PAUD. Hal ini terjadi, karena pada saat itu tidak ada orang yang mau untuk terlibat dalam pengelolaan PAUD. Sehingga akhirnya seperti pepatah tidak ada rotan, akarpun jadi.

Menyadari akan kemampuan yang mereka miliki masih kurang maka mereka mengharapkan untuk bisa mengikuti kursus-kursus atau pelatihan-pelatihan tentang PAUD, namun keinginan untuk itu belum terwujud, karena sekarang memang tidak ada lagi kegiatan pelatihan-peltihan semacam itu. Maka dari itu, upaya yang bisa mereka lakukan adalah dengan belajar mandiri, seperti membaca buku-buku yang berkaitan 
dengan metode pembelajaran untuk anak-anak PAUD yang banyak dikeluarkan oleh Dinas Pendidikan Nasional Provinsi Bengkulu.

Mereka para tenaga pendidik (guru), menyadari kalau mendidik anak-anak PAUD berbeda dengan mendidik anak-anak Sekolah Dasar. Berdasarkan literatur-literatur (bukubuku) yang mereka baca, dalam proses pembelajarannya, mereka melaksanakannya berdasarkan pendekatan sebagai berikut: (1) berorientasi pada kebutuhan anak, (2) Belajar melalui bermain, (3) Kreatif dan inovatif, (4) Lingkungan yang kondusif, (5) Menggunakan Pembelajaran terpadu, (6) Mengembangkan Ketrampilan hidup, (7) Menggunakan berbagai media dan sumber belajar dan terakhir (8) Pembelajaran berorientasi pada prinsip Perkembangan anak (Suprapti, 2007: 31).

Tim PPM menyadari akan keterbatasan dari para tenaga pendidik (guru) PAUD ini, maka dalam hal pembinaannya maka Tim PPM melakukan semacam diskusi atau dialog dengan mereka. Dalam sesi ini Tim PPM menanyakan kepada mereka, apa yang sudah mereka lakukan dalam pelaksaan proses belajar mengajarnya. Dan akhirnya Tim PPM memberikan masukan-masukan kepada mereka bagaimana sebaiknya menghadapi anakanak PAUD. Karena Program PAUD didasarkan atas prinsip-prinsip, (1) Berorientasi pada kebutuhan anak, (2) Kegiatan belajar dilakukan melalui bermain, (3) Merangsang munculnya kreatifitas, (4) Menyediakan lingkungan yang mendukung proses belajar, (5) Mengembangkan kecakapan hidup anak, (6) Menggunakan berbagai sumber dan media belajar yang ada di lingkungan sekitar, (7) Dilaksanakan secara bertahap dengan mengacu pada prinsip perkembangan anak, (8) Rangsangan pendidikan mencakup semua aspek perkembangan. Semua itu Tim PPM jelaskan kepada mereka, tenaga pendidik (guru) (Gutama, 2006; 4).

Tim PPM kemudian menjelaskan bahwa tujuan dari pembelajaran di PAUD ini adalah dapat mengembangkan berbagai potensi anak sejak dini sebagai persiapan untuk masa depannya dan dapat menyesuaikan diri dengan lingkungan serta secara khusus bertujuan: (a) Anak mampu mengenal dan Percaya Tuhan, (b) Anak memiliki nilai moral, sikap dan budi pekerti yang baik, (c) Anak mampu mengelola dan mengontrol ketrampilan tubuh termasuk gerakan halus dan gerakan kasar serta mampu menerima rangsangan sensorik (panca indra), (d) Anak mampu menggunakan bahasa untuk pemahaman bahasa pasif dan dapat berkomunikasi secara efektif yang bermanfaat untuk berfikir dan belajar, (e) Anak mampu berfikir kreatif, logis, kritis, memberi alasan, memecahkan masalah dan menemukan sebab akibat, (f) Anak memiliki ketrampilan hidup (life skill) untuk membentuk kemandirian anak (g) Anak mampu mengenal lingkungan alam, sosial, peranan masyarakat dan menghargai keragaman sosial budaya, serta mampu mengembangkan konsep diri, rasa memiliki dan sikap positif terhadap belajar (Gutama, 2006:10).

Harapan dari Tim PPM, dengan melakukan kegiatan dialog dan diskusi ini para tenaga pendidik (guru) mampu menerapkan pada anak-anak PAUD sehingga apa yang diharapkan orangtua menitipkan anaknya di PAUD sesuai dengan apa yang diharapkan. 
Dalam pelaksanaan kegiatan proses belajar mengajar di PAUD "Peduli Anak Bangsa" dalam seminggu hanya tiga (3) hari masuk belajar yaitu: Hari Senin, Selasa dan Rabu.

Sesuai dengan apa yang sudah disepakati antara Tim PPM dan para pengelola PAUD, bantuan yang dibutuhkan ialah bangku-bangku, dan buku-buku yang digunakan dalam proses belajar mengajar. Bangku-bangku sangat dibutuhkan karena selama ini dalam ruangan yang untuk belajar tidak ada bangku-bangku yang digunakan untuk menulis. Selama ini anak-anak kalau menulis langsung di lantai. Akibatnya anak-anak merasa sakit punggungnya karena harus membungkuk saat menulis. Sesuai dengan luas ruangan belajarnya maka bangku yang bisa diletakan hanya 6 buah bangku saja.

Bantuan lain yang berupa buku-buku telah Tim PPM usahakan dengan membeli buku-buku cerita rakyat, buku-buku cerita dunia, gambar-gambar buah-buahan, gambargambar binatang, buku-buku untuk mewarnai, puzzle, alat-alat permaian yang di dalam ruangan. Barang-barang itu di beli lewat agen buku CV. Media Utama dan Toko buku Magek jaya yang ada di jln. Salak Bengkulu. Barang-barang tersebut sangat membantu bagi para pendidik dan anak-anak dalam proses belajar mengajar.

Setelah barang-barang siap semua, maka kemudian Tim PPM datang ke lokasi pengabdian untuk menemui kepala Desa Pondok Kubang bapak Ispindi Said dan ketua PAUD bapak Nastion untuk membicarakan bagaimana PAUD itu agar dapat lebih berkembang lagi. Beberapa usulan muncul pada saat pertemuan tersebut seperti lebih mensosialisasikan lagi PAUD tersebut kepada warga Desa Pondok Kubang maupun desadesa yang ada di sekitarnya. Selain mengenai keberadaan PAUD tersebut, juga perlu disosialisasikan pentingnya anak-anak yang berumur antara 2-6 tahun agar di sekolahkan di PAUD ini. Karena anak-anak tersebut merupakan masa depan bagi para orangtua kalau mereka nanti berhasil dalam kehidupannya. Makanya berilah pendidikan yang sebaikbaiknya bagi putra-putrinya, dengan memasukkan ke lembaga PAUD ini.

Dengan semakin banyaknya warga desa yang menitipkan anaknya ke Lembaga PAUD ini, maka diharapkan para orangtua maupun warga desa yang lain merasa memilki PAUD tersebut. Apabila perasaan memiliki sudah tertanam di dalam hati para orangtua maupun para warga Desa Pondok Kubang, tentu mereka akan menjaga dan memelihara maupun untuk memperbaiki PAUD tersebut agar lebih bagus. Sumbangan secara sukarela merupakan langkah yang bagus untuk dilakukan. Sumbangan yang terkumpul nantinya bisa digunakan untuk memperbaiki dinding PAUD yang kondisinya sudah bolong-bolong.

Sekarang ini kalau, mengandalkan bantuan dari pemerintah maupun donatur dari lembaga swasta maupun badan-badan yang lain, sangatlah sulit. Hal ini sudah dilakukan oleh ketua PAUD dengan mengajukan beberapa proposal kepada instansi pemerintah maupun lembaga-lembaga yang lain, ternyata hasilnya sangat mengecewakan karena tidak ada tanggapan, atau balasan satu pun. Sehingga sekarang ini Ketua PAUD sudah bosan untuk membuat proposal-proposal. Sementara, dana dari LPPM UNIB pos-pos peruntukannya bukan untuk memperbaiki lokal atau gedung sekolah.

Berdasarkan kesepakatan dengan pengelola, ketua PAUD dan kepala desa Pondok Kubang, maka penyerahan semua barang-barang bantuan dilaksanakan pada hari Rabu 
tanggal 22 Oktober 2014 di tempat belajar PAUD. Penyerahan itu disaksikan oleh bapak kepala desa, ketua, para pendidik, para orangtua/wali murid dan anak-anak PAUD. Bantuan yang diserahkan selain bangku-bangku yang jumlahnya enam (6) buah, juga buku-buku, gambar-gambar, puzzle dan alat-alat peraga, sesuai dengan apa yang diminta dan dibutuhkan PAUD tersebut.

Bantuan buku-buku tersebut antara lain: buku cerita rakyat seperti: cerita Malin Kundang, Bawang Merah-bawang putih, Cinderella, Putri Salju. Dan buku-buku dongengnya antara lain: Dongeng Kancil dan Harimau, Anak Katak Yang Nakal, Bebek si Perenang yang Handal, Singa dan Seekor Tikus, Kelinci Si Penakut, Kelinci Sombong dan Kura-Kura, Kecerdikan Si Kancil, Anak Kera dan Burung Pipit, dan masih banyak gambar-gambar dan poster-poster yang semuanya bermanfaat bagi kelancaran dalam proses belajar mengajar.

Bantuan ini merupakan bantuan yang pertama kali diterima PAUD "Peduli Anak Bangsa" kelihatan sekali kalau mereka semua sangat gembira dan senang hati. Anak- anak tidak lagi menulis di lantai, dan para gurunya dapat memanfaatkan bulu-buku tersebut untuk bercerita di depan anak-anak. Dan dapat menjelaskan sesuatu dengan gambargambar atau dengan alat-alat peraga. Bahkan anak-anak untuk melatih ketrampilannya dapat bermain dengan puzzle dan alat-alat permainan yang lainnya.

Harapan dari Tim PPM adalah semoga bantuan-bantuan yang diserahkan dapat digunakan sebagaimana mestinya dan supaya dijaga, dipelihara, agar tidak cepat rusak. Begitu juga anak-anak PAUD juga diberitahu dan dinasehati agar menggunakan semua buku-buku atau barang-barang bantuan itu dengan baik atau hati-hati supaya tidak cepat robek atau rusak.

Setelah kegiatan pengabdian pada masyarakat ini selesai, semua pihak, seperti para pengelola, para tenaga pendidik (guru), ketua dan kepala desa Pondok Kubang maupun Tim PPM berharap tidak hanya berhenti sampai di sini saja, tetapi berharap semoga kegiatan ini dapat terus berlanjut. Karena kami Tim PPM merasa, masih banyak yang harus dibenahi dari PAUD ini. Namun kami Tim PPM tidak bisa berbuat banyak kalau tidak ada dana Bantuan dari LPPM UNIB sebagai sumber dananya.

\section{KESIMPULAN DAN SARAN}

\section{Kesimpulan}

Kegiatan pengababdian pada masyarakat yang dilakukan oleh Tim PPM jurusan Sosiologi Fisip pada PAUD "Peduli Anak Bangsa" yang berlokasi di desa Pondok Kubang sudah selesai dilaksanakan. Tujuan kegiatan Pengabdian Pada Masyarakat juga sudah terlaksana semua. Pembinaan sudah dilakukan, meskipun dengan cara berdialog dan berdiskusi dengan para tenaga pendidik (guru) mengenai metode pembelajaran yang seperti apa yang digunakan. Kemudian Tim PPM memberikan masukan-masukan mengenai tujuan dan prinsip-prinsip apa yng harus ada di pembelajaran di PAUD. Bantuan 
berupa bangku-bangku dan bermacam-macam buku cerita, gambar-gambar dan alat-alat peraga sudah diserahkan semua, dan sesuai dengan permintaan dari pengelola PAUD.

\section{Saran}

Dengan selesainya kegiatan PPM ini, maka dapat disarankan sebagai berikut:

1. Dengan melihat kondisi PAUD yang sangat memprihatinkan ini (dindingnya yang bolong-bolong) maka sebaiknya warga desa Pondok Kubang secara sukarela diminta untuk memberi uang sumbangan untuk memperbaiki PAUD tersebut.

2. Sebaiknya waktu belajar di PAUD ditambah lagi, jangan hanya 3 hari (Senin, Selasa dan Rabu) saja, tetapi bisa sampai hari Jum'at, seperti PAUD-PAUD yang lainnya.

\section{UCAPAN TERIMA KASIH}

Dengan telah selesainya kegiatan pengabdian pada masyarakat ini, Tim PPM mengucapkan terima kasih kepada pimpinan Universitas Bengkulu yang telah mengalokasikan anggaran DIPA 2014, guna membiayai seluruh kegiatan pengabdian ini. Selain itu, Tim PPM juga mengapresiasi Ketua beserta segenap Staf Lembaga Penelitian dan Pengabdian Pada Masyarakat Universitas Bengkulu atas penilaian, pemantauan dan fasilitasi administrasi dari awal kegiatan hingga kegiatan pengabdian ini selesai. Terakhir kepada bapak Kepala Desa Pondok Kubang, Ketua dan para tenaga pendidik (guru), para orangtua dan anak-anak PAUD yang telah bekerjasama dan mendukung kegiatan pengabdian ini dari awal hingga akhir.

\section{DAFTAR PUSTAKA}

Gutama, 2006, Pedoman Teknis Penyelenggaraan Taman Penitipan Anak, Depdiknas, Direktorat Jenderal Pendidikan Luar Sekolah Direktorat Pendidikan Anak Usia Dini. Suprapti, 2009, Modul Pengembangan Kurikulum Pendidikan Anak Usia Dini, Bidang Pedidikan Non Formal Dan Informal Dinas Pendidikan Provinsi Bengkulu. Undang-Undang Sistem Pendidikan Nasional Nomor 20 Tahun 2003. 